\title{
Samuel Beckett y el teatro de la palabra ausente
}

Lucas Margarit

Universidad de Buenos Aires

\begin{abstract}
Resumo
Neste trabalho exporemos aspectos da poética de Samuel Beckett que serão projetados para um teatro onde o silêncio é provavelmente o fator mais importante da representação. A impossibilidade de dizer e a representação de uma realidade mental de natureza linguística levarão o seu teatro a expor uma série de situações onde as personagens se encontrarão quase imóveis, colocando a ação nas palavras que constroem imagens mentais centradas de diferentes maneiras no silêncio.
\end{abstract}

Palavras-chave: Beckett; realidade mental; voz

\begin{abstract}
In this paper we work on some subjects of Samuel Beckett's poetics. They will be projected to a theater where silence is, perhaps, the most important factor of the performance. The inability to say and the representation of mental reality of linguistic nature, take its theater to expose situations where the characters find almost motionless, placing the action in the words that build mental images or break through them.
\end{abstract}

Key words: Beckett; mental reality; voice 
1. Es interesante pensar en la relación que se establece entre filosofía y poesía, la cual es un elemento central en el pensamiento de Heidegger, Gadamer, María Zambrano, Eduardo Nicol, etc. Por lo general se plantea que la poesía se acerca más a aquello que el filósofo calla. Los casos en que pudimos apreciar esta problemática en forma más notoria es en los poemas de Heidegger y en los textos poéticos de María Zambrano. -le cris silencieux "je suis» que l'os entend, dont le pierre meurt, dont croit mourir ci qui

ne fut jamais-

René Daumal

Comenzaremos con un ejemplo que a Beckett quizá le hubiera interesado. Si, para la teoría científica, el origen del tiempo se produjo a raíz de una explosión representada por la onomatopeya Big Bang, es posible sospechar que el tiempo en el cual estamos inmersos tiene su principio en el ruido. Como contraparte, en el Génesis bíblico, en forma más poética y metafísica, se relata este comienzo a partir de la enunciación del Verbo que crea. La relación, entonces, que podríamos establecer a partir de estos dos enunciados, tiene un doble camino: en primer lugar, el binomio silencio-ruido que se aleja de la palabra articulada y, en segundo lugar, la relación silencio-palabra que lleva consigo la problemática de la demarcación de un yo que enuncia y que, por consiguiente, es (adquiere una identidad) en el silencio. Todo ello resulta paradójico. Sin embargo, tras estos dos recorridos, el silencio queda relegado a un instante anterior a la historia y, sospechosamente, al lenguaje. Más adelante, a lo largo de la historia del pensamiento, será uno de los motores de la reflexión poética y filosófica así como también de la creación, ya sea literaria, musical o, incluso, plástica. Desde los místicos medievales hasta los poetas contemporáneos, encontramos la cuestión de la relación del lenguaje con el contexto social e intelectual, es decir, con el mundo y los elementos que rodean a quien enuncia. Esta problemática sugiere que el hombre, dado su lugar en el mundo, recibió como imposición la tarea de nombrar, facultad que posee y que, de alguna manera, parece justificar su relación con el universo, su pertenencia a él y, en algún sentido, también las formas de su apropiación.

Así pues, entre los místicos, encontramos un intento de decir esa búsqueda a través del nombre de Dios, uno de los problemas centrales de la tradición judeo-cristiana. Entre los filósofos y los poetas, cada uno con sus diferencias ${ }^{1}$, el punto de mira cambia para centrarse en la búsqueda del nombre de las cosas y la relación que este nombre establece con su objeto. En esta relación, cuando la creencia se concentra en una perfecta conjunción entre la palabra y la cosa, ésta se torna hegemónica y cree poseer la autoridad de una verdad. Una vez consciente de que existe un defasaje entre estos elementos, la noción de un discurso unívoco y una verdad absoluta quedan abolidas. Tanto el filósofo como el poeta, se internan en este campo de incertidumbres y reflexionan sobre su material de trabajo, el lenguaje. Si la verdad queda descartada de la acción discursiva, el silencio se hace presente como referencia ineludible de esa verdad que no es expresada o, mejor dicho, que no 
puede ser expresada, tal como lo plantea Beckett en numerosas oportunidades que ya mencionamos. Sin embargo, en su caso, no se plantea una verdad que deba enunciarse, sino un dilema respecto del lenguaje y sus posibilidades: la experiencia individual, que al ser individual no se manifiesta como verdad absoluta sino como relativa, es atravesada por el lenguaje, y luego es enmarcada y delimitada en su expresión. El murmullo que se impone al sujeto limita las posibilidades de la enunciación. Beckett utiliza este límite como el espacio de poiesis: el sujeto poético sabe que lo que obtiene de ese fluir continuo del lenguaje son sólo restos que quedan depositados en el fondo de la memoria, como el detritus. Por ello, los recuerdos de los personajes beckettianos y la enunciación que presenta en sus poemas, corresponde a un recuerdo del lenguaje y no de los acontecimientos, un artificio literario que le daría mayor peso a la voz que enuncia que al sujeto en sí mismo. De allí que el cuerpo aparezca muchas veces como inmóvil o ausente y la presencia se manifieste desde el hecho poético o dramático a través de una voz. Una voz que enuncia una ausencia de articulación dialógica en muchas de sus últimas obras teatrales, sus dramatículas. Es interesante, en este aspecto, pensar sus obras para televisión, Eh Joe (1965), por ejemplo, donde la voz es expuesta desde la mente del personaje afirmando el silencio del espacio donde se encuentra. Una obra que nos lleva a preguntarnos con Maurice Blanchot, ¿de dónde proviene esa voz?

La pregunta que podríamos hacernos frente a semejante planteo, siguiendo una de las lecturas fundamentales de Beckett, el pensamiento del Fritz Mauthner, se vincula con las posibles manifestaciones de la comunicación y sería la siguiente, ¿qué correspondencia se puede establecer entre el mundo y las palabras? ¿qué particularidad tiene cada uso de la palabra que la convierte en algo absolutamente personal frente a la palabra del otro? O, si por el contrario, es necesario y, a veces, obligatorio callar ante el mundo para que las cosas ingresen en el discurso por medio de su silencio. Beckett detecta en los personajesde muchas de sus obras un sujeto condenado a expresar. Si el mundo está separado del yo-sujeto, las cosas no interfieren directamente en el discurso sino únicamente como experiencia de lenguaje, como un defasaje que deja una zona libre de interpretación, en suma, la no correspondencia entre las palabras y su objeto relativo. En forma paradójica, también podríamos concebir el lenguaje como una "cosa" en el mundo $\mathrm{y}$, consecuentemente, cómo deviene en objeto de su propio decir ya que es, bajo esta perspectiva esbozada por Beckett, la experiencia más segura que tiene el emisor en cuanto estructura textual. La pregunta quedaría formulada de la siguiente manera, ¿qué dice el lenguaje de sí mismo en cuanto cosa? Inevitablemente, también hay una zona indeterminada donde
2. BLANCHOT, Maurice. El libro que vendrá, 1969, p. 237. 
3. BLANCHOT, Maurice.

Sobre la angustia en el lenguaje, 1979, p. 8.

4. Cf. MAUTHNER, Fritz. Contribuciones a una crítica del lenguaje, 1976, p. 110 y ss. Cabe aclarar que en el (W)Horoscope Notebook (c. 1930), manuscrito RUL 3000, que se encuentra en el Archivo Beckett de la Universidad de Reading, Inglaterra, Beckett copió a mano extensos párrafos de esta obra, que leyó a fines de los años 1920 con James Joyce.

5. Se ha experimentado numerosas veces la posibilidad de la aislación, pero obviamente en el momento de percibir ese silencio aislado, escuchamos los sonidos de nuestro organismo. John Cage, cuenta su experiencia y señala el sonido del corazón como perturbación de ese silencio "artificial". el silencio se hace presente. En su ensayo acerca de la angustia del lenguaje $e^{3}$, Blanchot señala la grieta que se abre entre el deseo del poeta y su propia escritura, enfatizando así el silencio que, necesariamente, se establece en todo texto, un silencio que podría tornarse aún más extremo si lo llevamos al accionar de cualquier enunciación. Si, como decía Mauthner, el lenguaje tiene su origen en una estructura metafórica ${ }^{4}$, cada enunciación presentaría una perspectiva distinta del mundo, así como también una recepción individual y única de cada enunciado. Tanto el emisor como el receptor se ubicarían en niveles de sentido diferentes pese a que utilicen un código en común. En realidad, es imposible que dos percepciones de la realidad resulten idénticas y puedan ser compartidas puesto que las relaciones entre ese lenguaje individual y las cosas tampoco suelen ser idénticas. En su obra, Beckett hace hincapié en esa relación oblicua entre el lenguaje y el mundo si bien, en el caso particular que estamos tratando, nos muestra una separación casi concluyente entre estas dos instancias. Así pues, la escritura enmarcaría un silencio que particulariza cada discurso puesto que se produce por un defasaje siempre diferente en cada enunciación, según cada sujeto. Este silencio puede ser entendido como el secreto que, ineludiblemente, guarda y oculta toda escritura y que se manifiesta como una sutil sugerencia. El dramaturgo posee la palabra y, por su naturaleza, debe llevar consigo también el silencio, de la misma manera que el músico establece una relación entre los sonidos y los silencios: existe una solución de continuidad entre estas dos instancias de la enunciación, ya que poseer uno es arriesgarse en el otro. "Callar" es guardar las palabras, "decir" es exponer el silencio.

La obra de Beckett recupera esta última instancia de exposición del silencio y lo hace a partir de una poética que se funda en la elipsis. Su escritura, que como acción se desenvuelve en el vaciamiento y en el despojo, recupera esa vacilación entre el decir y el desnombrar. Si el silencio en estado puro no puede ser percibido fácticamente ${ }^{5}$, y por lo tanto quizás, puede ser sólo imaginado como concepto, lo que nos queda es únicamente su representación artificiosa e, incluso, una suerte de experiencia individual y no comunicable. Frente a esta reflexión, se nos abre un interrogante: ¿cómo representarlo con palabras? ¿cómo llevarlo a escena?, es decir, ¿cómo hacerlo con un elemento que parece su opuesto pero que también es su complementario? Nos encontramos ante la representación de lo "irrepresentable" que, en la literatura, se producirá a través de las palabras, aquéllas que, paradójicamente, lo constituyen. Las obras de Beckett emergen de una noción de irrepresentabilidad que vislumbró a partir de una expresión imposible. En realidad, debemos reconocer que nos encontramos frente a un elemento similar al silencio, es decir, frente a una representa- 
ción donde lo impronunciable ocurre en un doble sentido. Por un lado, si el silencio es pronunciado, obviamente, dejaría de ser silencio ya que en su propia naturaleza se encuentra la "inpronunciabilidad". Por otro lado, es imposible que sea pronunciado porque su lugar es el origen, permanece en el momento anterior al instante en que el lenguaje comienza a marcar su diferencia con lo "otro" en su enunciación, si bien cumple la función de delimitación de esa misma voz poética. De tal manera, se trata de un silencio que se ubicaría más allá de nuestras posibilidades de mera actitud discursiva. La existencia de las palabras, mediada por la mirada de nuestra naturaleza como seres discursivos, se encontraría sometida a la impureza del silencio mientras nuestro conocimiento del aquél se encuentra minado por la experiencia en sí que modifica y, de algún modo, establece nuestro lenguaje.

Como ya se ha tratado en numerosas ocasiones ${ }^{6}$, la repetición también se vuelve un claro ejemplo del desnombrar en la obra de Beckett, sin embargo, la estructura sintagmática que elegirá más bien aludirá a otra experiencia con el lenguaje que no se relaciona con la neutralidad del sentido, sino con un discurrir hacia el menos. La exposición de este vaciamiento de la enuncición discursiva sobre la escena alude a la manifestación de lo silencioso. Respecto de ello, Mauthner afirma, "mientras la poesía sea poesía tendrá contornos inseguros"7, aludiendo, justamente, a la caída de ese discurso cerrado, listo para entrar con esa incomunicabilidad del texto dramático en un espacio de apertura del sentido a través de su manifestación. Invariablemente y en primer lugar, el texto beckettiano induce a mirar hacia la superficie callada del texto por cuanto "leer" sería simplemente observar detrás de las palabras e imaginar (o re-elaborar) el silencio que ellas esconden, ya sea como secreto o imposibilidad. Así, el pensamiento entra en diálogo con el texto y se extiende fuera de los límites de la posible enunciación, ya que el texto es el desarrollo de un pensar fuera de él que a su vez es silenciado y enmascarado con palabras.

Si pensamos que uno de los vocablos latinos que alude a "prohibición” es la palabra interdico, podríamos pensar que el silencio (lo callado) es, metafóricamente, aquello que está en medio de lo dicho y que no es lo enunciado, sino lo silenciado o, en su defecto, lo que debe ser silenciado. Si todo texto en cuanto enunciación es exposición de un silencio que está siempre presente, todo decir es una metáfora de la muerte, de aquello que calla absolutamente. En la obra Rockaby $(1979)^{8}$, que podemos considerar un "poema escénico", Beckett crea la imagen de un callar casi absoluto por detrás de una voz: la mujer, sentada en su mecedora que espera y sólo dice "more" para pedir más lenguaje y de este modo alejar (y a su vez acercar en su experiencia particular) el silencio que puede sentir a través
6. Cf. el excelente libro de Steve Connor, Samuel Beckett: Repetition, Theory and Text, 1988. Incluso el de Christopher Ricks, Beckett 's Dying Words, 1993, donde se establece la relación palabra / muerte / despojamiento.

7. MAUTHNER, Fritz, Contribuciones a una crítica del lenguaje, 1976, p.109.

8. BECKETT, Samuel. Collected Shorter Plays, 1984, p. 271. 
9. ABATE DINOUART, El arte de callar, 2000 .

10. Ibidem, p.51.

11. Ibidem, p.51. de las palabras con el fin de que generen -tal como ocurre con todos los personajes beckettianos-una pantalla que la separe de esa nada a la que se encuentra expuesta. En este sentido, decir implica alejarse de un espacio real, es agonizar y, por lo tanto, entrar en una disputa con la experiencia de lo silencioso en estado puro porque no es posible hablar de esa experiencia y porque sólo contamos con un parecer desde la muerte del otro. A partir de nuestra perspectiva, es decir, a partir del lugar donde se presenta la posibilidad de decir, el silencio se aleja de las palabras de la misma manera que la muerte se acerca a cada sujeto. Por otra parte, deberíamos considerar también, con respecto a esta dramatícula, que para Beckett el pensamiento tiene forma de lenguaje, por lo tanto, son esas palabras encerradas en el cráneo (skull) las que nos atraviesan y también las que producen la realidad mental de muchos de sus personajes. Beckett expone en muchos de sus monólogos esa articulación silenciosa de la palabra que es el pensar. Esta mujer, vestida de negro, en su mecedora, nos conduce directamente hacia el silencio de su caja craneana, y de ese modo, se hace cuerpo (representación) ese silencio en el que está sumida la anciana. Ella pide palabras que son lo único que puede asegurar su pensamiento, y por lo tanto su continuidad en el mundo.

Si variamos el punto de mira y tomamos un pequeño tratado de fines de siglo XVIII, El arte de callar del Abbé Dinouart ${ }^{9}$, observaremos que el silencio es un valor que se vincula con lo dicho, que establece un vínculo estrecho con las retóricas y que se muestra como una forma de recuperar el buen decir con el aprendizaje del callar. Dice Dinouart, "el tiempo de callar debe ser el primero cronológicamente y nunca se sabrá hablar bien si antes no se ha aprendido a callar" ${ }^{10}$. Así pues, el comienzo del aprendizaje se remonta al momento en que se decide no decir, con lo cual, implícitamente, alude a las fallas que el lenguaje acarrea. A este respecto, la necesidad del silencio también representa el buen uso de las palabras: decir es demostrar la intuición que uno tiene del silencio, acercarse a la enunciación desde la precavida experiencia del callar porque "sólo se debe dejar de callar cuando se tiene algo que decir más valioso que el silencio"11. Este acto volitivo privilegia el lugar del silencio frente al de la palabra, una instancia que es anterior a toda enunciación y que nos lleva por el camino de una interrogación más escéptica, pero también más poética: ¿hay algo más valioso que el silencio? Para dar respuesta, en principio, deberíamos decir que hay tres tipos de silencio. En primer lugar, lo que se calla volitivamente o el secreto, en segundo lugar, lo que es imposible decir o el misterio y, en tercer lugar, lo que no se debe decir. En los tres casos, las palabras manifiestan metáforas de sus posibilidades e imposibilidades por medio de diferentes recursos como la perífrasis, la metáfo- 
ra, la sinécdoque, etc. Cuando Wittgenstein, en su proposición más famosa del Tractatus Logico Philosophicus, plantea: "De lo que no se puede hablar hay que callar" ${ }^{\prime 2}$, en realidad, se acerca al tono de la literatura mística ${ }^{13} \mathrm{y}$, sin proponérselo en primera instancia, recupera una mirada diferente del pensar más allá de los límites de la estructura lógica que propone. En este punto, surge una variante del postulado blanchotiano, el límite entre el pensar y el decir. Debemos considerar que existe, empero, una instancia anterior, el nombrar o, en palabras de Franco Rella, "ningún otro lenguaje, sino el del hombre, es nombrante" 14 . El nombre en sí permite que el lenguaje ingrese, teóricamente, en el ámbito de lo comunicable. Frente a esto, el lenguaje poético, dada su naturaleza, rescata en ese nombrar por primera vez, no sólo la ausencia del objeto, sino ante todo el silencio de las cosas. Como aclaramos con respecto a la obra de Beckett, si las cosas están fuera del alcance de la percepción del sujeto, cuando se nombra se está creando lenguaje (o uso de lenguaje) y es, en este uso, que la distancia con el mundo se hace cada vez más notoria. Pensemos en la obra Act Without Words $I(1956)^{15}$, donde nos encontramos con un único personaje que intenta alcanzar una serie de objetos que descienden sobre la escena. El hombre es empujado al mundo y enviado a apropiarse de cada uno de esos objetos. El deseo se manifiesta en la imposibilidad de alcanzarlos, pero también en el hecho de no hablar, de no nombrar a ninguno de ellos. Callar, es en esta obra exponer también el rito silencioso de la acción dramática pero también vital. Nombrar implicaría, así, apropiarse del objeto, paradójicamente, en su ausencia a fin de poder, según Beckett, "rasgar y atravesar" el nombre que alguna vez ese objeto tuvo. Nombrar, sería de este modo, alejar la cosa para aprehender el lenguaje junto al silencio que le da forma a ese murmullo incesante. Entre el mundo que cada individuo cree conocer (es decir, conoce mal ${ }^{16}$ ) y las mismas palabras se encuentra este silencio que constituye tanto al mundo y sus cosas como al lenguaje y sus pausas necesarias. Indudablemente, el silencio es un elemento en que colaboran ambas partes. Una obra sin palabras es también poner en evidencia las posibilidades del drama ante el propio despojamiento que Beckett realiza con respecto a la materia que moldea: las palabras. El silencio es en este caso la imposibilidad de acceder a través de la palabra a esa realidad que rodea al sujeto. No es necesario hablar, el cuerpo se dispone a actuar y no encuentra necesidad en el decir, en exponer ese pensamiento que constituye su propia realidad interior.

El dramaturgo puede conocer el silencio del mundo a través de las palabras. Como ya hemos visto, en Beckett está presente una posición solipsista donde el sujeto se encuentra apartado del mundo y donde el tratamiento del binomio cuer-
12. WITTTGENSTEIN, Ludwig.

Tractatus Logico-Philosophicus, 1997, parág. 7.

\section{Ver WITTGENSTEIN,}

Ludwig, Tractatus Logico-

Philosophicus, 1997, parág. 6.522.

14. RELLA, Franco. El silencio y las palabras, 1992, p.168.

15. BECKETT, Samuel, Collected Shorter Plays, 1984, p. 41.

16. Y, siguiendo a Beckett, podemos agregar que si conoce mal aquello que percibe, no conoce al objeto de su percepción en absoluto. 
17. VON HOFFMANSTHAL, Hugo. La carta de Lord Chandosy algunos poemas, 1990.

18. BECKETT, Samuel. Collected Shorter Plays, 1984, p. 209. po/mente será una evidente herencia de su lectura de las obras de Descartes, Malebranche y Geulincx. Si el mundo es percibido erróneamente, cada vez que nombra, siempre lo hace por primera vez, olvidando, por variaciones particulares, el posible nombre original de las cosas. Por otro lado, cada sujeto estaría en una posición similar y compartiría con el resto esa zona silenciosa del discurso y la experiencia. Se sabe que hay algo allá - tal como afirma en su poema something there - que no puede ser identificado porque, precisamente, no puede ser bien percibido ni nombrado por una palabra que pueda ser compartida. Una actitud igual de radical se encuentra en la Carta de Lord Chandos de von Hoffmansthal ${ }^{17}$, donde un escritor se precipita al abandono de su escritura poética. Paradójicamente, los textos dicen el callar y, en muchos casos, toman la palabra del otro para decir su propio silencio. Las palabras ya pronunciadas por otro devienen en cosas del mundo, pero con un silencio particular que tal apropiación rescata. En el caso del austríaco, tomar la voz epistolar de Lord Chandos -con la distancia temporal y espacial que esto supone- daría cuenta de una distancia necesaria en la apropiación de la voz del otro para decir su silenciar el lenguaje. El poeta toma partido por el abandono de sus palabras y recupera la noción de silencio primordial del cual se alejó por su escritura: en este silencio se encuentra la muerte. El poeta calla su no pertenencia al lenguaje y, a la vez, lo enuncia para apropiarse de las palabras. Quizá, nos esté planteando que, para poder ser, uno está condenado a las palabras. El silencio, de este modo, resultaría impensable fuera de los límites del lenguaje. Su sonoridad, cuando enuncia, se transforma en la estructura que lo lleva hacia su propio límite mientras que al poeta lo conduce hasta el límite de lo indecible, una condena de la cual Beckett se hará cargo, alejándose de la visión mística de la prohibición y de la imposibilidad, para ingresar con una mirada reflexiva sobre las palabras y la obligación de decir. Su teatro, de esta manera, se dirige hacia una representación que se constituye a partir de aquello que se calla, aquello que está más allá del horizonte de representación lingüística. La vida y la muerte como los extremos de un espacio silenciado por la misma experiencia del sujeto que construye su realidad mental. Si tomamos su obra Breath $(1969)^{18}$, entre el llanto inicial y la exhalación final sólo queda ese silencio que en la posición de "inter-dicto", nos señala la relación silenciosa del sujeto con el mundo.

Desde sus comienzos, la obra de Samuel Beckett reconoce que es imposible decir con la estructura cartesiana. La estructura mental del personaje en Murphy es una elocuente prueba de ello: necesita aislarse del mundo para sentir su identidad en forma plena, se aísla con unas bufandas, tapa sus ojos, sus oídos, inmoviliza su cuerpo en una silla y termina con 
la descripción de ese aislamiento, "then it set him free in his mind" ${ }^{19}$. En su producción posterior, Beckett ya no describirá el aislamiento, sino que, simplemente, escribirá y presentará la soledad del personaje. La memoria, parte indudable de su complejo sistema literario, aparece como forjadora de un presente de enunciación de la propia identidad y particularidad del personaje. El aparato reflexivo sabe que lo dicho no es lo que se quiere decir puesto que el silencio, en la concepción misma del fracaso beckettiano, termina con una posición extrema: para decir, se niega a decir y, finalmente, se hace la pregunta comment dire. Este silencio se corporiza cuando somete al lenguaje a su propio despojamiento, cuando aparece en el vaciamiento del signo y la estructura poética tras un desarrollo que será recurrente en toda su obra. Recordemos que Beckett abandona su lengua oficial, el inglés, para -entre otras cosas- renunciar al uso automático de una retórica que lo encierra en una estructura textual que lo desborda. La imagen de un lenguaje que debe ser rasgado ${ }^{20}$ nos enfrenta nuevamente con la búsqueda de aquello que el lenguaje calla y esconde en su enunciación. Beckett plantea la posibilidad de la Nada, homologada aquí a ese silencio inicial a partir del cual aprendemos a decir. Se trata de un valor poético en tanto sugerencia de sentido o de un eje en su escritura que parte de las grietas y hiatos que arroja el lenguaje: una escritura del hueco y el simulacro.

En Company (1979), por ejemplo, el narrador simula un diálogo y, en esta simulación, expone sólo un callar puesto que las palabras quedan guardadas para sí mismo en una estructura dialógica de pensamiento. Un elemento importante en esta mutación es la memoria de quien enuncia, por caso, de ese narrador indeterminado que asume el protagonismo de su propio pensamiento, con todo, sólo puede constituírse como "sujeto" a partir de la percepción de sí mismo como otro, es decir, construyéndose a sí mismo como relato o como ficción. La problemática planteada a partir de esta duplicación del sujeto es la falta de vinculación entre los dos términos ya que "ese otro" es un referente vacío: no hay otra manera de decir más que sobre sí mismo, llevando a la narración hacia la imposibilidad de presentar el conocimiento del mundo más allá del propio pensamiento de quien narra, en última instancia, hacia una realidad que pertenece a su mundo interior y que, por lo tanto, no puede ser dicha. La memoria se convierte así, no en recuerdo de una experiencia, sino en recuerdo de un lenguaje que se levanta frente a un telón de fondo silencioso y cuya extensión -metafóricamente hablando- se mide a partir de las paredes del cráneo del sujeto. Las palabras construyen un pasado en el relato, desnudan las tramas del texto y formulan la manera en que esa voz piensa cómo decir bajo un silencio indeterminado por la experiencia fáctica, pero condicionado por
19. Idem. Murphy, 1993, p.6.

20. BECKETT, Samuel. Disjecta, 1983, p. 171. 
21. BECKETT, Samuel. Poèmes suivi de Mirlitonnade, 1982, p. 36. la experiencia lingüística. En este sentido, podríamos pensar en "Comment dire" (1989) como un soliloquio através del cual un sujeto se cuestiona su lugar de enunciación. Esta idea irá trasladando el poema hacia el silencio, encontrando un punto de enunciación en el balbuceo y el murmullo que, de por sí, ya es un casi decir y un casi callar. La voz que intenta recuperar el habla articulada lo hace desde aquellos recursos que parecen desarticularla: repetición, verso cortado, etc. En el sistema del poema, el silencio hace su aparición en esos guiones que acompañan a las palabras y sentencian el sentido del fracaso de la enunciación. Si retomamos los binomios ruido-silencio y palabra-silencio planteados anteriormente, podremos observar que allí se forja una variable que remite al movimiento-quietud, puesto que todo movimiento implica sonido y toda quietud prefigura el silencio. A partir de esta perspectiva, los personajes de Beckett buscan el silencio desde la inmovilidad e intentan dar cuenta de una realidad interior por medio de las palabras que enmarcan su pensamiento. Si comparamos algunos poemas de Echo's Bones con los escritos del tercer período, veremos que se produce también un detenimiento en la voz poética, es decir, poemas como "Enueg I" o "Enueg II" presentan un recorrido espacial con una percepción primaria del paisaje que es reelaborada en el texto. Sin embargo, si tomamos textos posteriores, observaremos que la voz que enuncia presenta una inmovilidad notoria que se corresponde con el lugar secundario que ocupa el sujeto con respecto a las palabras: en esta instancia de la poética beckettiana, se establece un movimiento mínimo que se origina en el discurso del pensamiento y la autonomía que las palabras parecen adquirir.

Por otra parte, es en Mirlitonnades donde Beckett reflexiona sobre estas cuestiones a partir de otra óptica: la voz del poeta se fragmenta, entra en un estado más íntimo de la reflexión poética y, en este ensimismamiento, el silencio se apropia de las palabras y la voz poética intenta aferrarse a ellas tras el murmullo que desea alejarse del silencio o del callar.
silence tel que ce qui fut avant jamais ne sera plus par le murmure déchiré d'une parole sans passé $d^{\prime}$ avoir trop dit $n$ 'en pouvant plus jurant de ne se taire plus ${ }^{21}$

En este poema, las palabras se presentan como un balbuceo producido por el abandono de su lengua y el ingreso a una nueva por la que siente extrañeza, la distancia entre las palabras y las cosas se muestra más evidente que nunca. En este despojamiento, encontramos que las palabras hablan de las palabras mientras el silencio se desliza por entre ellas. La voz se inser- 
ta en un espacio de enunciación y pretende no callar jamás. El deseo, una vez más, se ve invadido por la palabra que lo dice y que, consecuentemente, lo aleja de su concreción. A partir de este fracaso, el silencio aparece como la fundamentación de un uso del lenguaje y como la obligación de decir que hace al poeta: en palabras de Blanchot, un "decir" para no morir. Sin embargo, esta caracterización de la voz poética se irá esparciendo y fragmentando a lo largo de la obra poética de Beckett, dando lugar a una voz intimista y cada vez más cercana al cuestionamiento por la enunciación y por la imposibilidad de decir. El poeta se ve ante la disyuntiva de callar y en la obligación de expresar, una condena que une a Beckett con la figura de Lord Chandos. No disponer de material a partir del cual expresar lo llevará a escribir desde el agotamiento ${ }^{22}$, la obligación de este último poema: si no hay qué decir, el texto poético declara ese impedimento, no a un nivel semántico, sino en el plano de la composición textual. La postura de Samuel Beckett se centra en la reflexión sobre las posibilidades que tiene el poeta para “expresar" mientras se aleja de la mística y se acerca a una visión fáctica de las posibilidades del lenguaje como vehículo de conocimiento y comunicación. El poeta no calla, sino que expone su silencio a través de las palabras, como si se tratase de una necesidad por escapar del vacío. Beckett recurre a la imposibilidad del decir para hablar del decir, y quiebra la relación cotidiana con los objetos, intercalando aquello que forma el origen y la necesidad de la escritura: el silencio. Estamos, ahora, frente a una palabra que se dice en su propia ausencia, en su despojo y en su simulacro. Quizás se trate de otra insospechada representación del silencio que, por su alteridad, se manifiesta como su propio fracaso.
22. Esta idea de la literatura del agotamiento la tomo del artículo de John Barth, "Literatura del agotamiento", en Jaime ALAZRAKI (ed.) J.L.Borges. El escritory la crítica, 1976, pp.170-182 


\section{Referencias}

ABATE DINOUART. El arte de callar, Madrid: Siruela, 2000.

BARTH. John. Literatura del agotamiento, in ALAZRAKI, Jaime (ed.) J.L.Borges. El escritor y la crítica, Madrid: Taurus, 1976, pp.170-182

BECKETT, Samuel. Collected Shorter Plays, London: Faber \& Faber, 1984.

. Murphy, London: Calder, 1993.

. Disjecta, London: John Calder, 1983.

Poèmes suivi de Mirlitonnades, Paris: Minuit, 1982.

BLANCHOT, Maurice. El libro que vendrá, Caracas: Monte Ávila, 1969.

"Sobre la angustia en el lenguaje". In: Falsos Pasos, Valencia: Pre-textos, 1979, p. 8.

CONNOR, Steve. Samuel Beckett: Repetition, Theory and Text, Oxford: Blackwell, 1988. RICKS, Christopehr. Beckett 's Dying Words, Oxford: OUP, 1993.

MAUTHNER, Fritz. Contribuciones a una crítica del lenguaje, México: Juan Pablos, 1976

RELLA, Franco, El silencio y las palabras, Barcelona: Paidós, 1992

VONHOFFMANSTHAL, Hugo, La carta de Lord Chandos y algunos poemas, México: F.C.E., 1990.

WITTGENSTEIN, Ludwig, Tractatus Logico-Philosophicus, Barcelona: Altaya, 1997. 